\title{
Populatiegerichte eerstelijnszorg in internationaal perspectief
}

\section{Van Alma Ata en Ottawa naar Astana}

\author{
Chris van Weel · Maria van den Muijsenbergh
}

Published online: 11 February 2019

(C) The Author(s) 2019

In de Alma Ata-verklaring uit 1978 erkende de WHO het belang van een sterke populatiegerichte eerstelijnszorg: alle mensen in alle landen hebben een fundamenteel recht op gezondheid en regeringen hebben de verantwoordelijkheid om dat recht te realiseren. De visie die in de verklaring verwoord werd betekende een verandering van ziektegericht denken naar aandacht voor de sociaaleconomische en omgevingsfactoren die gezondheid beïnvloeden.

\section{De Alma Ata-verklaring}

In de bijeenkomst in Alma Ata in 1978 stelden de WHO-lidstaten voor het eerst dat versterking van de 'primary health care' de belangrijkste strategie is om toegang tot goede gezondheidszorg voor iedereen te bereiken [1]. Geleid door waarden van solidariteit en sociale rechtvaardigheid was men het erover eens dat alle mensen in alle landen een fundamenteel recht op gezondheid hebben en dat regeringen de verantwoordelijkheid hebben om dat recht te realiseren. De aandacht kwam nu te liggen op de sociaaleconomische en omgevingsfactoren die gezondheid beïnvloeden.

Voor dit artikel gebruiken we voor 'primary healthcare' de term 'basisgezondheidszorg' of 'primaire gezondheidszorg', die eerstelijnsgezondheidszorg en

C. van Weel · M. van den Muijsenbergh $(\bowtie)$

Radboud Institute of Health Sciences, Afdeling

Eerstelijnsgeneeskunde, Radboud Universitair Medisch Centrum, Nijmegen, Nederland

Maria.vandenMuijsenbergh@radboudumc.nl

C. van Weel

Department of Health Services Research and Policy,

Australian National University, Canberra, Australië

M. van den Muijsenbergh

Pharos, expertisecentrum gezondheidsverschillen, Utrecht, Nederland openbare gezondheidszorg omvat. Basisgezondheidszorg leunt op drie pijlers: versterking van de gemeenschap ('community empowerment'), multisectorieel beleid en actie, integratie van eerstelijnszorg en publieke gezondheidzorg [2]. De Alma Ata-verklaring vormde een referentiepunt voor gezondheidszorghervormingen die zich sindsdien in veel landen hebben voltrokken.

\section{De Ottawa Charter}

Voortbouwend op de uitgangspunten van de Alma Ata-verklaring werd in 1986 de Ottawa Charter ondertekend, die de uitgangspunten voor effectieve gezondheidsbevordering beschrijft [3]. Gezondheidsbevordering betreft het proces dat mensen in staat stelt om de controle over hun gezondheid te versterken en zo hun gezondheid te verbeteren. Gezondheid wordt daarbij gezien als een bron voor het leven van elke dag, niet als een doel op zich, waarbij aandacht is voor zowel de sociale en persoonlijke, als fysieke mogelijkheden. Gezondheidsbevordering is daarom niet alleen een verantwoordelijkheid van de gezondheidszorg, maar strekt zich uit van leefstijl tot algemeen welzijn. De Ottawa Charter vormde een volgende mijlpaal in het denken over gezondheid, waarvan de kernelementen nog altijd te herkennen zijn in veel activiteiten, ook van de Nederlandse publieke gezondheidszorg.

\section{De Astana-verklaring}

Het uiteindelijke doel, universele toegang tot goede zorg en breed gedragen regie over de eigen gezondheid, is echter nog niet behaald. Politieke onwil en toch een focus op ziektegerichte zorg en projecten liggen daaraan ten grondslag [4]. Daarom is het verheugend dat dit streven zeer recentelijk een nieuwe 
impuls heeft gekregen dankzij de verklaring van Astana [5].

Op 27 oktober 2018 schaarden de regeringen van alle 196 WHO-lidstaten zich achter deze verklaring, die opnieuw oproept tot het versterken van de primaire gezondheidszorg, als noodzakelijke voorwaarde om de toegankelijkheid tot goede, samenhangende zorg en gezondheid te vergroten [3]. Deze verklaring is vernoemd naar de plaats waar de regeringsvertegenwoordigers onder leiding van de WHO samenkwamen: Astana in Kazachstan.

Een sterke primaire gezondheidszorg, zoals hierboven gedefinieerd een combinatie van de 'Nederlandse' eerstelijnszorg en lokale publieke gezondheidzorg, dient de kern te vormen van het gezondheidszorgstelsel. Hierin vinden preventie en zorg plaats voor de meeste gezondheidsproblemen en van hieruit wordt samenwerking met andere maatschappelijke sectoren gezocht om de sociale determinanten van gezondheid te adresseren [6].

Vanzelfsprekend zijn in de verklaring van Astana de ervaringen en inzichten verwerkt die de afgelopen veertig jaar zijn opgedaan. Zo is inmiddels duidelijk dat een sterke eerste lijn leidt tot grotere kosteneffectiviteit van de gezondheidszorg: betere gezondheid voor lagere gezondheidszorgkosten [7-9]. Deze evidence vormde een belangrijke aansporing voor de WHO voor een hernieuwde focus op eerstelijnsgezondheidszorg [10], met daarin een oproep om te investeren in de opleiding en werkomstandigheden van professionals in de eerste lijn, zoals verpleegkundigen, verloskundigen en huisartsen [11]. Een sterke eerste lijn, preventie en zorg dichtbij huis, vormt daarbij de kernstructuur om toegang tot gezondheidszorg voor iedereen te kunnen garanderen [12].

\section{Astana - wat is nieuw?}

De Astana-verklaring is geënt op wetenschappelijke evidentie en het voortschrijdend inzicht dat zich sinds Alma Ata heeft ontwikkeld. Zo weet men nu dat het in 1978 gelanceerde concept werkt en onder verschillende sociaaleconomische en culturele omstandigheden tot betere gezondheid van de populatie leidt. Behalve op de bovengenoemde kosteneffectiviteitsonderzoeken is dit inzicht gebaseerd op een aantal aansprekende succesverhalen - in het bijzonder de indrukwekkende verbetering van populatiegezondheid via een versterking van de eerstelijnsgezondheidszorg in Brazilië en Thailand [13-15].

Naast deze met het gezondheidszorgbeleid samenhangende zaken speelt Astana ook in op een bredere internationale ontwikkeling. De Verenigde Naties richt zich namelijk met de Sustainable Development Goals op het versterken van welvaart in een toekomstbestendige wereld [16]. Een van zeventien doelstellingen is het bevorderen van gezondheid als voorwaarde voor sociaaleconomische ontwikkeling, waardoor deze doelstelling bijdraagt aan een brede maat- schappelijke waarde en, niet zoals ten tijde van Alma Ata, beperkt blijft tot de gezondheidszorg. Een belangrijke daarmee samenhangende voorwaarde is dat veilige gezondheidszorg van hoge kwaliteit toegankelijk is voor iedereen, zonder onacceptabele financiële lasten: Universal Health Coverage [12, 17]. Een belangrijk verschil met Alma Ata is dan ook dat de in Astana geformuleerde doelstellingen zijn ingebed in een mondiale ambitie, die naast gezondheid en gezondheidszorg ook sociale, economische en maatschappelijke ontwikkeling nastreeft, en dat daar behalve de Verenigde Naties nog andere invloedrijke partijen bij betrokken zijn, zoals de Wereldbank en de Bill en Melinda Gates-stichting. Dit brede draagvlak maakt het mogelijk om stelselhervormingen te agenderen binnen een brede context van maatschappelijke hervormingen, en garandeert meer dan Alma Ata dat concrete resultaten worden gerealiseerd.

\section{Leerpunten van Alma Ata}

Achteraf kan het natuurlijk als opmerkelijk worden gezien dat de verklaring van Alma Ata, die zo sterk was gericht op gemeenschappelijke acties vanuit de gezondheidszorg samen met andere maatschappelijke sectoren, het product was van uitsluitend de gezondheidszorgsector zelf. Dat is waarschijnlijk een van de factoren waardoor het na 1978 nog lang heeft geduurd voordat er wereldwijd concrete gezondheidszorghervormingen op gang kwamen.

Dit is een waardevolle leerervaring voor het implementeren van 'Astana', waarbij deze kritische reflectie niet mag verhullen hoe conceptueel verrijkend de visie op gezondheidszorg was die in 1978 werd gepresenteerd. Het was voor het eerst dat met internationaal gezag gesteld werd dat de gezondheidsnoden van individuen en populaties centraal dienden te staan, en dat een integrale benadering van preventie en het aanpakken van sociale determinanten van gezondheid relevanter is dan uitsluitend een hoogtechnologische zorg gericht op ziektebeelden. Deze visie vormde de opmaat tot een paradigmaverandering in de gezondheidszorg, de opleiding van professionals en het onderzoek ter onderbouwing van de te leveren zorg.

De hierin bepleitte collectieve benadering stond haaks op het politieke beleid van individualisering en liberalisering dat enkele jaren later mondiaal opgeld deed. Dit is ontegenzeggelijk een belangrijke beperkende factor geweest bij de politieke implementatie van de verklaring. Zonder de illusie te koesteren dat het mondiale politieke klimaat waarin de verklaring van Astana landt ideaal is, zijn er toch aanwijzingen dat een beroep op collectiviteit en de aanpak van sociale determinanten momenteel weer hogere prioriteit krijgen.

Ook bij 'Astana' is het de vraag hoe de balans gevonden kan worden tussen de korte en lange termijn. Waar gezondheidszorgbeleid een kwestie is van lange 
adem, doen gezondheidsproblemen van het individu en de populatie dagelijks een appel op snelle actie. In reactie op 'Alma Ata' heeft dit geleid tot het introduceren van 'beperkte eerstelijnsgezondheidszorg': het aanbieden van een aantal programma's gericht op een beperkt aantal gezondheidsproblemen, zoals vaccinaties, verloskundige zorg en zorg voor pasgeborenen. Deze programma's waren op zich aanvankelijk succesvol, bijvoorbeeld in Sri Lanka [18]. Het probleem was echter dat ze tot verticale programmering leidden, zonder onderling verband, zodat er enige jaren later geen basis bleek te zijn voor een responsieve zorg voor een verouderende bevolking [19]. Voor duurzame zorg is horizontale integratie essentieel, waarin preventie, behandeling en zorg voor alle gezondheidsproblemen bij alle categorieën patiënten, in alle stadia zijn samengebracht.

Een andere reden waardoor de doelen van Alma Ata niet gerealiseerd werden, is dat de complexiteit van primaire gezondheidszorg onvoldoende werd onderkend. In het beleid werd het vaak als een container gezien, waar naar believen taken aan kunnen worden toegevoegd zonder gelijktijdig te investeren. Daarmee samenhangend sloot het beleid onvoldoende aan op de competenties van de eerstelijnsprofessionals en hun missie. Zo investeerden veel landen wel in de specifieke opleiding van huisartsen, maar ze stonden tegelijkertijd toe dat ook andere medisch specialisten rechtstreeks toegankelijk zijn en daarmee een 'eerstelijnsfunctie' vervullen [20].

Dit gebrek aan begrip komt ook tot uitdrukking in de verwarring die de Engelstalige begrippen 'primary health care' en 'primary care' oproepen. De termen worden vaak als synoniem door elkaar gebruikt, maar soms ook als tegenstellingen of competitieve benaderingen. Met primary care (hier vertaald als 'eerstelijnszorg') wordt bedoeld de praktijk van zorg en behandeling voor individuen, als functie binnen de gezondheidszorg, terwijl primary health care ('primaire gezondheidszorg') verwijst naar het opereren met andere maatschappelijke voorzieningen (multisectorieel) en publieke gezondheidszorg. Cruciaal voor de kracht van primary health care is dat de eigenstandige functie in de gezondheidszorg - primary care - daarvoor essentieel is en aan beide functies in samenhang recht moet worden gedaan.

\section{Astana - van standpunt naar succes}

De verklaring van Astana lijkt op een goed moment te komen, waarin de politieke ontvankelijkheid voor toekomstbestendig(e) welzijn en welvaart lijkt toe te nemen, en er veel empirisch verkregen inzichten beschikbaar zijn over het versterken van de primaire gezondheidszorg en eerstelijnszorg. Punt van zorg is daarbij wel dat kerncijfers over het functioneren van de gezondheidszorg voorbijgaan aan de waarden die de eerste lijn tot stand brengt: continuïteit van zorg, persoons- en populatiegerichtheid, op behoeften ge- richte zorg, samenhangende zorg. Om een betrouwbaar beeld te krijgen van de effecten van versterking van de eerste lijn is het nodig over indicatoren te beschikken die deze waarden kunnen vatten [21], en de ontwikkeling van deze indicatoren zal in belangrijke mate het succes van 'Astana' bepalen. Daarnaast is het cruciaal om de complexiteit van primaire gezondheidszorg beter te doorgronden en te vertalen naar beleid. Deze bestaat uit de organische samenhang van zorg voor individuen in praktijk en spreekkamer, met acties in andere maatschappelijke sectoren, gericht op preventie en bevordering van gezondheid en welzijn.

Open Access This article is distributed under the terms of the Creative Commons Attribution 4.0 International License (http://creativecommons.org/licenses/by/4.0/), which permits unrestricted use, distribution, and reproduction in any medium, provided you give appropriate credit to the original author(s) and the source, provide a link to the Creative Commons license, and indicate if changes were made.

\section{Literatuur}

1. World Health Organisation. Declaration of Alma Ata 1978. Geneva: WHO, 1978. www.who.int/publications/almaata declaration_en.pdf. Geraadpleegd op 10 december 2018.

2. Ghebreyesus TA, Fare H, Birtanov Y, et al. Primary health care for the 21st century, universal health coverage, and the sustainable development goals. Lancet. 2018;392:1371-2.

3. World Health Organisation. Ottawa charter for health promotion. Genève: WHO; 1986.

4. The Lancet. The Astana declaration: the future of primary health care. Editorial. Lancet. 2018;392:1369.

5. World Health Organisation. Astana declaration from AlmaAta towards universal health coverage and the sustainable development goals 25-26 october 2018. Astana, Kazakhstan: WHO. 2018. https://www.who.int/docs/defaultsource/primary-health/declaration/gcphc-declaration. pdf. Geraadpleegd op: 10 dec 2018.

6. Commission on Social Determinants of Health. Closing the gap in a generation: health equity through action on the social determinants of health. Genève: World Health Organization. 2008. http://apps.who.int/ iris/bitstream/handle/10665/43943/9789241563703_eng. pdf;jsessionid=4B2D91D4D9AC4E0188108B8C846F953A? sequence $=1$. Geraadpleegd op: $10 \operatorname{dec} 2018$.

7. Starfield B. Is primary care essential? Lancet. 1994;344: 1129-33.

8. Starfield B, Shi L, Macinko J. Contribution of primary care to health systems and health. MilbankQ. 2005;83:457-502.

9. Kringos D. The strength of primary care in Europe. Proefschrift. Utrecht: Universiteit Utrecht; 2012.

10. World Health Organisation. The world health report 2008 primary health care, now more than ever. Genève: WHO; 2008.

11. World Health Organisation. Sixty-second world health assembly. Resolution WHA62.12. Primary health care, including health system strengthening. Genève: WHO; 2009.

12. World Health Organisation. Universal health coverage. Geneva: WHO, 2018. http://www.who.int/universal_health_ coverage/en/. Geraadpleegd op 10 december 2018.

13. Schilling Mendonça C. The Brazilian unified health system: primary health care in action. In: Kidd MR, redactie. 
The contribution of family medicine to improving health systems: a guidebook from the World Organization of Family Doctors. 2e druk. Abingdon: Radcliffe; 2013.

14. Macinko J, Guanais FC, De Fátima M, et al. Evaluation of theimpact of theFamily Health Program on infantmortality in Brazil, 1990-2002. J Epidemiol Community Health. 2006;60:13-9.

15. Pongsupap Y. Family medicine and community orientation as a new approach of quality primary care in Thailand. In: Kidd MR, redactie. The contribution of family medicine to improving health systems: a guidebook from the World Organization of Family Doctors. 2e druk. Abington: Radcliffe; 2013.

16. Verenigde Naties. Sustainable development goals. New York: VN, 2018. https://www.un.org/sustainabledevelop ment/. Geraadpleegd op 10 december 2018.
17. Jha A, Godlee F, Abbasi K. Delivering on the promise of universal health coverage. BMJ.2016;353:i2216.

18. Hewa S. Sri Lanka's approach to primary healthcare: a success story in South Asia. Galle Med J.2011;16:24-30.

19. Weel C van, Kassai R, Qidwai W, et al. Primary healthcare policy implementation in South Asia. BMJ Glob Health. 2016;1:e57.

20. Weel C van, Kassai R. Expanding primary care in South and EastAsia. BMJ. 2017;356:j634.

21. Veillard J, Cowling K, Bitton A, et al. Better Measurement for Performance Improvement in Low- and Middle-Income Countries: The Primary Health Care Performance Initiative (PHCPI) Experience of Conceptual Framework Development and Indicator Selection. Milbank Q 2017;95:83683. 